\title{
Exposure to biomass smoke, cigarettes, and alcohol modifies the association between tumour necrosis factor (-308G/A, -238G/A) polymorphisms and tuberculosis in Mexican carriers
}

\author{
Israel Torres Ramírez de Arellano ${ }^{1}$, Citlaltepetl Salinas Lara ${ }^{1}$, Luz María Torres Espíndola², \\ Manuel de Jesús Castillejós López ${ }^{3}$, Aurelio Jara Prado ${ }^{1}$, Rafael Velazquez Cruz ${ }^{4}$, \\ Jorge L Guerrero Camacho ${ }^{1}$, Nelly Patiño ${ }^{5}$, Jesús D. Rembao Bojórquez ${ }^{1}$, Martha Lilia Tena Suck ${ }^{1}$
}

\begin{abstract}
${ }^{1}$ Department of Pathology, National Institute of Neurology and Neurosurgery Manuel Velasco Suarez, Mexico City, Mexico

${ }^{2}$ Pharmacology Laboratory, National Institute of Paediatrics, Mexico City, Mexico ${ }^{3}$ Epidemiological Surveillance Unit, National Institute of Respiratory Diseases, Mexico City, Mexico

${ }^{4}$ Genomics of Bone Metabolism Laboratory, National Institute of Genomic Medicine (INMEGEN), Mexico City, Mexico

${ }^{5}$ Subdirection of Development of Clinical Applications, National Institute of Genomic Medicine (INMEGEN), Mexico City, Mexico
\end{abstract}

Submitted: 21 June 2018

Accepted: 8 October 2018

Arch Med Sci 2020; 16 (3): 672-681

DOI: https://doi.org/10.5114/aoms.2020.92673

Copyright (c) 2020 Termedia \& Banach

\section{Abstract}

Introduction: Exposure to biomass smoke, cigarettes, alcohol, and the impairment of immunoregulation are considered to be risk factors for tuberculosis. Tumour necrosis factor (TNF) $-308 \mathrm{G} / \mathrm{A}$ and $-238 \mathrm{G} / \mathrm{A}$ gene polymorphisms have been associated with tuberculosis. However, the results remain inconsistent. The aim of this study was to determine the association between TNF polymorphisms and tuberculosis in the presence of biomass smoke, cigarettes, and alcohol in a Mexican population.

Material and methods: TNF polymorphisms were determined in 118 tuberculosis patients and 223 controls. We performed a univariate, bivariate, stratified analysis. Odds ratios, confidence intervals, and $p$-values were calculated. Results: Occupational biomass smoke exposure was associated with tuberculosis between the patients and controls $(\mathrm{OR}=1.70,95 \% \mathrm{Cl}: 1.08-2.70$, $p=0.02)$. We also found an association of the $-308 \mathrm{~A}$ allele carriers between the patients and controls without exposure to occupational $(p=0.04, \mathrm{OR}=0.16$, $95 \% \mathrm{Cl}: 0.01-0.92)$ and in-home $(p=0.02, \mathrm{OR}=0.14,95 \% \mathrm{Cl}: 0.01-0.81)$ biomass smoke, as well as an association with alcohol $(p=0.01, \mathrm{OR}=0.24$, 95\% Cl: $0.05-0.75)$. The haplotype analysis revealed an association of the $-308 \mathrm{~A} /-238 \mathrm{G}$ haplotype between patients and nonconsanguineous controls without exposure to occupational ( $p=0.02, \mathrm{OR}=0.12,95 \% \mathrm{Cl}: 0.01-0.99$ ) and in-home ( $p=0.01, \mathrm{OR}=0.1,95 \% \mathrm{Cl}$ : 0.01-0.9) biomass smoke, cigarette use $(p=0.04, \mathrm{OR}=0.28,95 \% \mathrm{Cl}: 0.08-0.98)$, and alcohol $(p=0.02, \mathrm{OR}=0.22$, $95 \% \mathrm{Cl}: 0.05-0.88)$ intake.

Conclusions: The TNF $-308 \mathrm{~A}$ allele and the $-308 \mathrm{~A} /-238 \mathrm{G}$ haplotype are associated with tuberculosis, as are exposure to biomass smoke, cigarettes, and alcohol. No association for the $-238 G / A$ polymorphism was found. Our results provide insight into a possible protective role of TNF polymorphisms in tuberculosis in our population.

Key words: tuberculosis, biomass smoke, cigarette, alcohol, polymorphisms, protection, risk.

\section{Corresponding author:} Manuel de Jesús Castillejós López, PhD Instituto Nacional de Enfermedades Respiratorias Calzada de Tlalpan 4052 Col. Secc. XVI, Deleg. Tla 14080, Ciudad de México Mexico

E-mail: mcastillejos@gmail.com 


\section{Introduction}

Smoking is considered to be a risk factor for tuberculosis, among other diseases [1, 2], which increases with consumption [3]. An immune response in the lungs is induced by cigarette smoke, recruiting inflammatory cells such as macrophages and $\mathrm{T}\left(\mathrm{CD} 8^{*}\right)$ lymphocytes. Macrophages are the main defence cells in nonsmokers; bronchoalveolar aspiration in smokers (when compared with nonsmokers) shows a fivefold increase in the number of inflammatory cells in the lungs, with $85-90 \%$ being macrophages [4].

A few studies have evaluated the impact of biomass smoke as a risk factor for tuberculosis. Either occupational or house environment contaminations due to cooking with solid fuels (wood or charcoal) are responsible for respiratory diseases in children and adults [5]. High levels of gaseous compounds and solid particle concentrations within the breathable size range are present in this type of smoke; these compounds are thought to be more harmful to humans [6].

An association between alcohol intake and tuberculosis has also been found; namely, that heavy drinkers have more tuberculosis relapses [7], a worse prognosis, and a higher probability of suffering more destructive forms of tuberculosis [8, 9]. Immunoregulation impairment, involving cytokines, caused by alcohol intake is one of the main risk factors for tuberculosis as well as other pathologies that develop from immunodeficiency, making individuals vulnerable to infectious agents in different tissues [10,11].

Recently, tumor necrosis factor $\alpha$ (TNF- $\alpha)$ has been associated with heavy alcohol intake [12]. An increased production of cytokines by blood monocytes and Kupffer cells in alcoholic steatosis patients and in animal models with alcohol-induced liver damage has been shown [13-15]. Additionally, excessive TNF- $\alpha$ production depends on the amount of alcohol ingested [16].

In addition to wood smoke, cigarette, and alcohol exposure, genetic factors can alter interindividual cytokine levels [3]. Two polymorphisms in the promoter region of the TNF gene affect its expression: a negative gene regulation that diminishes TNF- $\alpha$ production is caused by the TNF-238G/A polymorphism [17], and an increase in production up to fivefold the basal level is caused by the TNF $-308 \mathrm{G} / \mathrm{A}$ polymorphism [18]. Both polymorphisms have been identified as risk factors for different non-infectious and infectious diseases, including tuberculosis [1921]. However, the results remain inconsistent and contradictory $[22,23]$. The $T N F-308 A A$ genotype has been associated with the highest risk for mild airway diseases that could eventually progress to pulmonary obstructive disease [24]. The $-308 \mathrm{~A}$ allele has also been associated with pulmonary dis- ease susceptibility due to cigarette smoke [25]. The aim of this study was to determine the association between TNF polymorphisms and tuberculosis in the presence of biomass smoke, cigarettes, and alcohol.

\section{Material and methods}

\section{Study design and subjects}

We studied 118 tuberculosis patients and 223 inhome controls. Blood samples from all participants were taken at the National Institute of Respiratory Diseases, Mexico City. The controls were in-home contacts of the patients, all healthy individuals without a previous tuberculosis history, and they were enrolled at the same time as the patients. All cases were microbiologically confirmed according to World Health Organisation guidelines.

DNA was extracted from frozen blood using the salting out procedure without phenol extraction [26]. Briefly, red cells were lysed with TrisTriton-Sucrose buffer (TTS), then the DNA was extracted from lymphocytes with $5 \mathrm{mM} \mathrm{NaCl}, 1 \%$ sodium dodecyl sulphate (SDS), and saturated $\mathrm{NaCl}$ followed by deproteinisation with chloroform : isoamyl alcohol 24 : 1 and precipitation with absolute ethanol. Finally, DNA was dried out and resuspended in sterile water.

Demographic data on the participants were collected through interviews with professional personnel. The information collected included ethnicity, gender, age, biomass combustion exposure (fumes and asbestos for occupational smoke; wood or charcoal for in-home smoke), cigarettes, and alcohol intake. By analysing cooking habits, we classified between modern nonsolid (gas, electricity) and solid fuels (charcoal, wood). Subjects, who had cooked with charcoal or wood and worked with direct exposure to fumes and dust (asbestos) for the year prior to this study were classified as positive for biomass smoke exposure. Subjects with at least a 20-cigarette intake within the last 30 days or one cigarette per month for the last year were classified as smokers. There are questionnaires that consider positive alcohol consumption as the intake of $16 \mathrm{~g}$ a day [27] or $25 \mathrm{~g}$ per week [11]. However, we defined regular drinkers as those who drank 20 to 40 g per day. Informed consent was signed by all the subjects.

This study was approved by the Institutional Science and Bioethics Committee, code E-05-06.

\section{Genotyping}

Two TNF gene polymorphisms, previously associated with tuberculosis in European, Mexican American, Hispanic, and Latino populations, were selected $[19,28-31]$. TNF $-308 G / A$ and 
I. Torres Ramírez de Arellano, C. Salinas Lara, L.M. Torres Espíndola, M.J. Castillejós López, A. Jara Prado, R. Velazquez Cruz, J.L. Guerrero Camacho, N. Patiño, J.D. Rembao Bojórquez, M.L. Tena Suck
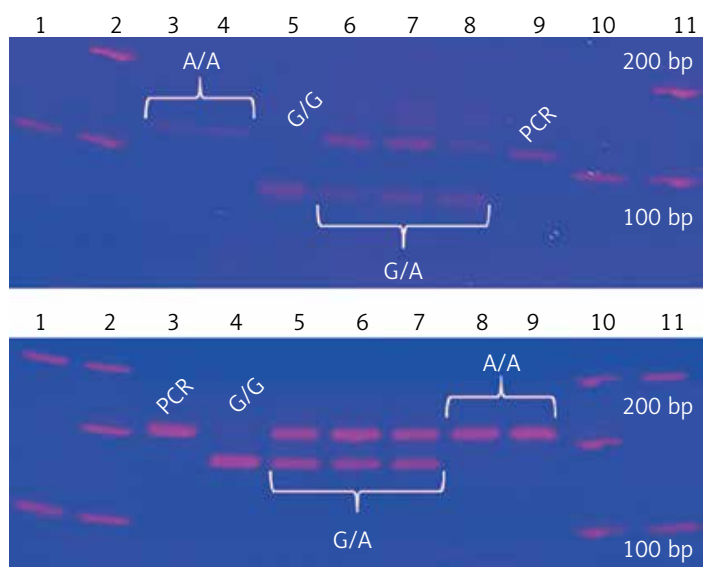

Figure 1. TNF genotypes by polymerase chain reaction and restriction fragment length polymorphisms. Upper image: $-308 \mathrm{G} / \mathrm{A}$. Lower image: $-238 \mathrm{G} / \mathrm{A}$

$-238 G / A$ gene polymorphisms were genotyped by polymerase chain reaction and restriction fragment length polymorphisms (PCR-RFLP) [32]. The $-308 G / A$ homozygous $A A$ genotype is identified by a 107 bp fragment, the GG genotype has a combination of 87 and 20 bp bands, and the heterozygous $G A$ has three bands $(107,87$, $20 \mathrm{bp})$. The $-238 A A$ polymorphic genotype is identified by a 152 bp fragment, the $G G$ wild type has two bands (133, $19 \mathrm{bp})$, and the heterozygous $G A$ has three fragments. Genotypes were confirmed by Sanger sequencing with an ABI Prism 3130 genetic analyser and ABI Prism BigDye Terminator $^{\circledast}$ V3.1 (Applied Biosystems, USA); each genotype was confirmed twice in a bidirectional way by PCR (Figure 1).

\section{Statistical analysis}

Calculated genotypic and allelic frequencies for both TNF polymorphisms in tuberculosis patients and controls were compared and the odds ratio (OR) between polymorphisms was evaluated. We also determined the possible gene-environment interaction between TNF polymorphisms and the exposure factors (biomass smoke, cigarettes, and alcohol). A univariate, bivariate, stratified analysis was performed, and using the $\chi^{2}$ test we calculated $p$-values in a case-control study design, allowing for the evaluation of the possible association between TNF polymorphisms and pulmonary tuberculosis susceptibility. Haplotype analysis with both TNF polymorphisms was also carried out. All the information gathered from each patient by SPSS version 20.0 (IBM, USA) software was stored in a database.

\section{Results}

We studied 118 patients with confirmed pulmonary tuberculosis (PTB) and 223 confirmed healthy controls (TC). One hundred and forty consanguineous contacts (CC) and 83 nonconsanguineous contacts (NCC) comprised the control group. All groups were in Hardy-Weinberg's equilibrium $(p>0.05)$. Genotypic and allelic frequencies for both polymorphisms for each group were calculated. Significant differences were found for the $T N F-308 G A$ genotype $(O R=0.35$, $95 \% \mathrm{Cl}: 0.13-0.93, p=0.03)$ and the $-308 A$ allele $(\mathrm{OR}=0.37,95 \% \mathrm{Cl}: 0.14-0.95, p=0.04)$ between nonconsanguineous carriers and tuberculosis patients. No association for the TNF $-238 G / A$ polymorphism was found. The results are shown in Table I.

Regarding the exposures studied, the median number of years of smoking was 17 (15-19.5), occupational exposure to fumes was 10 years (3-21), stove use in years was 18 (10-30), and alcohol intake time was also 18 years (10-25). Comparisons of PTB with CC, NC, and TC are shown in Table II. Significant $p$-values with risk OR for occupational biomass smoke exposure between patients, consanguineous controls, and total controls were obtained; in-home biomass smoke exposure had no association.

No association for the $-238 \mathrm{G} / \mathrm{A}$ polymorphism between patients and controls exposed to biomass smoke (occupational/in-home), cigarettes, and alcohol intake was found. In contrast, the statistical analysis results for the TNF $-308 \mathrm{G} / \mathrm{A}$ variant showed significant differences for the $-308 \mathrm{~A}$ allele carriers ( $G A$ and $A A$ genotypes) with protective OR between patients and controls without exposure to biomass smoke (occupational/in-home) and without alcohol intake. In regard to cigarette intake, an association was found only between patients and nonconsanguineous controls $(\mathrm{OR}=0.24$, 95\% Cl: 0.06-0.92, $p=0.02$ ) (Table III).

Of the four possible haplotypes ( $G G, A G, G A, A A)$ originated by the TNF polymorphisms $(-308 G / A$, $-238 G / A)$, only the $A G$ polymorphism had a significant association between patients and nonconsanguineous controls without exposure to the environmental factors studied here. The OR values obtained were of protection (Table IV). The analyses with haplotypes $G G$ and $G A$ are shown in the supplementary material (Tables $\mathrm{V}$ and $\mathrm{VI}$ ); no analysis was done with the $A A$ haplotype because it only had an $n=2$.

\section{Validation}

Randomly chosen samples $(n=12)$ for each genotype were validated by duplicated Sanger sequencing from PCR products, using Big Dye ${ }^{\mathrm{TM}}$ terminator v3.1 (Applied Biosystems), sequencing reactions were purified with Sephadex $650^{\circledR}$ (Sigma-Aldrich) and highly deionised Formamide $(\mathrm{Hi}-\mathrm{Di})^{\mathrm{TM}}$ (Applied Biosystems). Samples were analysed in an AB3130 Applied Biosystems genetic analyser (Figure 2). 
Table I. Genotypic and allelic frequencies for the TNF-308G/A polymorphism (A), TNF-238G/A polymorphism (B)

A

\begin{tabular}{|lcccc|}
\hline Genotype/allele & PTB & CC & NCC & TC \\
\hline$G G$ & $107(93.86)$ & $128(91.43)$ & $7=83, n(\%)$ & N $=223, n(\%)$ \\
\hline$G A$ & $7(6.14)$ & $11(7.86)$ & $13(15.66)^{\star}$ & $24(10.76)$ \\
\hline$A A$ & 0 & $1(0.71)$ & 0 & $1(0.45)$ \\
\hline$G$ & $221(96.93)$ & $267(95.36)$ & $153(92.17)$ & $420(94.17)$ \\
\hline$A$ & $7(3.07)$ & $13(4.64)$ & $13(7.83)^{\S}$ & $26(5.83)$ \\
\hline
\end{tabular}

$\chi^{2}, p<0.05 .{ }^{*} O R=0.35,95 \% \mathrm{Cl}: 0.13-0.93, p=0.03 .{ }^{\S} \mathrm{OR}=0.37,95 \% \mathrm{Cl}: 0.14-0.95, p=0.04$. PTB - tuberculosis patients, CC - consanguineous controls, NCC - nonconsanguineous controls, TC - total controls.

B

\begin{tabular}{|lcccc|}
\hline Genotype/allele & PTB & CC & NCC & TC \\
\hline$G G$ & $N=118, n(\%)$ & $N=139, n(\%)$ & $N=83, n(\%)$ & N $222, n(\%)$ \\
\hline$G A$ & $106(89.83)$ & $128(92.09)$ & $4(4.82)$ & $15(6.76)$ \\
\hline$A A$ & $11(9.32)$ & $11(7.91)$ & 0 & 0 \\
\hline$G$ & $1(0.85)$ & 0 & $162(97.59)$ & $429(96.62)$ \\
\hline$A$ & $223(94.49)$ & $267(96.04)$ & $4(2.41)$ & $15(3.38)$ \\
\hline
\end{tabular}

$\chi^{2}, p<0.05$. PTB - tuberculosis patients, CC - consanguineous controls, NCC - nonconsanguineous controls, TC - total controls.

Table II. Comparison of exposure factors between the different control groups and tuberculosis patients

\begin{tabular}{|c|c|c|c|c|c|c|c|c|}
\hline \multirow[t]{2}{*}{ Groups } & \multicolumn{2}{|c|}{$\begin{array}{l}\text { Occupational } \\
\text { biomass smoke }\end{array}$} & \multicolumn{2}{|c|}{$\begin{array}{c}\text { In-home } \\
\text { biomass smoke }\end{array}$} & \multicolumn{2}{|c|}{ Cigarette intake } & \multicolumn{2}{|c|}{ Alcohol intake } \\
\hline & $P$-value & OR $(95 \% \mathrm{Cl})$ & $P$-value & OR $(95 \% \mathrm{Cl})$ & $P$-value & OR $(95 \% \mathrm{Cl})$ & $P$-value & OR $(95 \% \mathrm{Cl})$ \\
\hline TBP vs. CC & 0.02 & $1.83(1.11-3.04)$ & 0.33 & $1.28(0.78-2.11)$ & 0.002 & $0.29(0.12-0.65)$ & 0.002 & $0.35(0.18-0.70)$ \\
\hline TBP vs. NCC & 0.16 & $1.51(0.85-2.69)$ & 0.54 & $0.84(0.47-1.48)$ & 0.0003 & $0.22(0.09-0.53)$ & 0.001 & $0.31(0.14-0.65)$ \\
\hline TBP vs. TC & 0.02 & $1.70(1.08-2.70)$ & 0.71 & $1.09(0.69-1.72)$ & 0.0003 & $0.26(0.12-0.57)$ & 0.001 & $0.33(0.17-0.64)$ \\
\hline
\end{tabular}

\section{Discussion}

We found that the presence of the TNF-308A allele is associated with tuberculosis $(\mathrm{OR}=0.37$, $95 \% \mathrm{Cl}: 0.14-0.95, p=0.04)$ in our Mexican sample. The same behaviour was observed (protective OR) with the -3086 A genotype carriers without exposure to biomass smoke, cigarettes, and alcohol. On the other hand, the $-308 \mathrm{~A} /$ $-238 G$ haplotype was also found to be a protective factor against tuberculosis in individuals not exposed to the environmental factors. These results are similar to previous findings that determined that the $-308 \mathrm{~A} /-238 \mathrm{G}$ haplotype gives protection against tuberculosis in Colombians [29]. Another study of a Greek population found that haplotypes other than GG have a protective effect against the development of sepsis [33]. This could be a result of the fact that every population may have favourable and unfavourable combinations of gene polymorphisms [34] and, in consequence, haplotypes. However, in our population, such protection is lost when exposed to biomass smoke, cigarettes, and alcohol. The explanation for this possibly involves several factors. Biomass smoke, cigarettes, and alcohol impair both the innate and adaptive pulmonary immune response, increasing an individual's susceptibility to infection by Mycobacterium tuberculosis and subsequent progression to active tuberculosis $[4,35$, 36]. Biofuel combustion generates compounds such as cytotoxic polycyclic aromatic hydrocarbons, which increase the secretion of proinflammatory cytokines, such as IL- $1 \beta$ and TNF- $\alpha$, by alveolar macrophages and pneumocytes. This secretion results in the inability to mount an ef- 
I. Torres Ramírez de Arellano, C. Salinas Lara, L.M. Torres Espíndola, M.J. Castillejós López, A. Jara Prado, R. Velazquez Cruz, J.L. Guerrero Camacho, N. Patiño, J.D. Rembao Bojórquez, M.L. Tena Suck

Table III. A - Genotype frequencies of the TNF -308G/A polymorphism without exposure to the environmental factors. B - Genotype frequencies of the $T N F-238 G / A$ polymorphism with exposure to the environmental factors. Comparisons were made between tuberculosis patients and each control group

A

\begin{tabular}{|c|c|c|c|c|c|}
\hline Exposure factor & Genotype & TBP & $\mathrm{CC}$ & $\mathrm{NCC}$ & $\mathrm{TC}$ \\
\hline \multirow[t]{4}{*}{ Occupational biomass smoke } & & $n=45$ & $n=76$ & $n=42$ & $n=118$ \\
\hline & $\mathrm{GG}, n(\%)$ & $44(97.8)$ & $69(90.8)$ & $34(81)$ & $103(87.3)$ \\
\hline & $\mathrm{GA}, n(\%)$ & $1(2.2)$ & $6(7.9)$ & $8(19)$ & $14(11.9)^{\S}$ \\
\hline & AA, $n(\%)$ & 0 & $1(1.3)$ & 0 & $1(0.8)$ \\
\hline \multirow[t]{4}{*}{ In-home biomass smoke } & & $n=55$ & $n=79$ & $n=39$ & $n=118$ \\
\hline & GG, $n(\%)$ & $54(98.2)$ & $72(91.1)$ & $32(82.1)$ & $104(88.1)$ \\
\hline & $\mathrm{GA}, n(\%)$ & $1(1.8)$ & $6(7.6)$ & 7 (17.9) & $13(11)^{*}$ \\
\hline & AA, $n(\%)$ & 0 & $1(1.3)$ & 0 & $1(0.9)$ \\
\hline \multirow[t]{4}{*}{ Cigarette intake } & & $n=98$ & $n=106$ & $n=60$ & $n=166$ \\
\hline & $\mathrm{GG}, n(\%)$ & $94(95.9)$ & $98(92.5)$ & $51(85)$ & $149(89.8)$ \\
\hline & $\mathrm{GA}, n(\%)$ & $4(4.1)$ & $7(6.6)$ & $9(15)^{\star}$ & $16(9.6)$ \\
\hline & $\mathrm{AA}, n(\%)$ & 0 & $1(0.9)$ & 0 & $1(0.6)$ \\
\hline \multirow[t]{4}{*}{ Alcohol intake } & & $n=95$ & $n=99$ & $n=57$ & $n=156$ \\
\hline & $\mathrm{GG}, n(\%)$ & $92(96.8)$ & $90(90.9)$ & $47(82.5)$ & $137(87.8)$ \\
\hline & $\mathrm{GA}, n(\%)$ & $3(3.2)$ & $8(8.1)$ & $10(17.5)$ & $18(11.6)^{\dagger}$ \\
\hline & $\mathrm{AA}, n(\%)$ & 0 & $1(1)$ & 0 & $1(0.6)$ \\
\hline
\end{tabular}

${ }^{\S} p=0.04, O R=0.16,95 \% \mathrm{Cl}: 0.01-0.92 ;{ }^{*} p=0.02, O R=0.14,95 \% \mathrm{Cl}: 0.01-0.81 ;{ }^{*} p=0.02$, OR $=0.24,95 \% \mathrm{Cl}: 0.06-0.92 ;{ }^{\dagger} p=0.01$, $O R=0.24,95 \% \mathrm{Cl}: 0.05-0.75$. PTB - tuberculosis patients, CC - consanguineous controls, NCC - nonconsanguineous controls, TC - total controls.

B

\begin{tabular}{|c|c|c|c|c|c|}
\hline Exposure factor & Genotype & TBP & $\mathrm{CC}$ & NCC & $\mathrm{TC}$ \\
\hline \multirow[t]{4}{*}{ Occupational biomass smoke } & & $n=61$ & $n=55$ & $n=39$ & $n=94$ \\
\hline & $\mathrm{GG}, n(\%)$ & $56(91.8)$ & $52(94.5)$ & $34(87.2)$ & $86(91.5)$ \\
\hline & $\mathrm{GA}, n(\%)$ & $5(8.2)$ & $3(5.5)$ & $5(12.8)$ & $8(8.5)$ \\
\hline & $\mathrm{AA}, n(\%)$ & 0 & 0 & 0 & 0 \\
\hline \multirow[t]{4}{*}{ In-home biomass smoke } & & $n=52$ & $n=54$ & $n=42$ & $n=96$ \\
\hline & GG, $n(\%)$ & $47(90.4)$ & $51(94.4)$ & $36(85.7)$ & 87 (90.6) \\
\hline & $\mathrm{GA}, n(\%)$ & $5(9.6)$ & $3(5.6)$ & $6(14.3)$ & $9(9.4)$ \\
\hline & AA, $n(\%)$ & 0 & 0 & 0 & 0 \\
\hline \multirow[t]{4}{*}{ Cigarette intake } & & $n=8$ & $n=26$ & $n=21$ & $n=47$ \\
\hline & $\mathrm{GG}, n(\%)$ & $6(75)$ & $24(92.3)$ & $17(81)$ & $41(87.2)$ \\
\hline & $\mathrm{GA}, n(\%)$ & $2(25)$ & $2(7.7)$ & 4 (19) & $6(12.8)$ \\
\hline & $\mathrm{AA}, n(\%)$ & 0 & 0 & 0 & 0 \\
\hline \multirow[t]{4}{*}{ Alcohol intake } & & $n=12$ & $n=34$ & $n=24$ & $n=58$ \\
\hline & GG, $n(\%)$ & $9(75)$ & $33(97.1)$ & $21(87.5)$ & $54(93.1)$ \\
\hline & GA, $n(\%)$ & $3(25)$ & $1(2.9)$ & $3(12.5)$ & $4(6.9)$ \\
\hline & $\mathrm{AA}, n(\%)$ & 0 & 0 & 0 & 0 \\
\hline
\end{tabular}

$\chi^{2}, p<0.05$. PTB - tuberculosis patients, CC - consanguineous controls, NCC - nonconsanguineous controls, TC - total controls. 
Exposure to biomass smoke, cigarettes, and alcohol modifies the association between tumour necrosis factor $(-308 \mathrm{G} / \mathrm{A},-238 \mathrm{G} / \mathrm{A})$ polymorphisms and tuberculosis in Mexican carriers

Table IV. TNF-308A/-238G haplotype associations between groups and exposure factors

\begin{tabular}{|c|c|c|c|c|c|}
\hline Group & Exposure & & $P$-value & OR & $95 \% \mathrm{Cl}$ \\
\hline \multirow[t]{8}{*}{ PTB vs. TC } & Occupational biomass smoke & $(+)$ & 0.91 & 0.93 & $0.29-3.00$ \\
\hline & & $(-)$ & 0.07 & 0.18 & $0.02-1.45$ \\
\hline & In-home biomass smoke & $(+)$ & 0.96 & 1.03 & $0.32-3.24$ \\
\hline & & $(-)$ & 0.049 & 0.16 & $0.02-1.27$ \\
\hline & Cigarettes & $(+)$ & 0.38 & 2.22 & $0.36-13.66$ \\
\hline & & $(-)$ & 0.13 & 0.42 & $0.14-1.31$ \\
\hline & Alcohol & $(+)$ & 0.27 & 2.25 & $0.51-9.95$ \\
\hline & & $(-)$ & 0.056 & 0.30 & $0.08-1.09$ \\
\hline \multirow[t]{8}{*}{ PTB vs. CC } & Occupational biomass smoke & $(+)$ & 0.62 & 1.45 & $0.33-6.41$ \\
\hline & & $(-)$ & 0.19 & 0.26 & $0.03-2.26$ \\
\hline & In-home biomass smoke & $(+)$ & 0.44 & 1.77 & $0.40-7.85$ \\
\hline & & $(-)$ & 0.13 & 0.22 & $0.02-1.86$ \\
\hline & Cigarettes & $(+)$ & 0.20 & 3.83 & $0.44-33.11$ \\
\hline & & $(-)$ & 0.40 & 0.58 & $0.16-2.06$ \\
\hline & Alcohol & $(+)$ & 0.08 & 4.75 & $0.71-31.86$ \\
\hline & & $(-)$ & 0.17 & 0.39 & $0.01-1.58$ \\
\hline \multirow[t]{8}{*}{ PTB vs. NCC } & Occupational biomass smoke & $(+)$ & 0.47 & 0.62 & $0.17-2.29$ \\
\hline & & $(-)$ & 0.02 & 0.12 & $0.01-0.99$ \\
\hline & In-home biomass smoke & $(+)$ & 0.50 & 0.65 & $0.18-2.31$ \\
\hline & & $(-)$ & 0.01 & 0.10 & $0.01-0.90$ \\
\hline & Cigarettes & $(+)$ & 0.72 & 1.42 & $0.20-9.82$ \\
\hline & & $(-)$ & 0.04 & 0.28 & $0.08-0.98$ \\
\hline & Alcohol & $(+)$ & 0.78 & 1.25 & $0.25-6.12$ \\
\hline & & $(-)$ & 0.02 & 0.22 & $0.05-0.88$ \\
\hline
\end{tabular}

PTB - tuberculosis patients, CC - consanguineous controls, NCC - nonconsanguineous controls, TC - total controls.

ficient immune response against infections [3739], as has been reported in Mexican, Canadian, and Chinese populations [40-42], despite these populations being very different from one other. This may suggest a common mechanism associated with an increased risk of pulmonary tuberculosis. On the other hand, the TNF - 308A allele increases expression up to fivefold from its basal levels [43], which favours granuloma formation [44]. The immune response against tuberculosis is mediated by $T$ lymphocytes, whose main function is the activation of macrophages and other cells [45]. Exposure to one or more of these factors (TNF polymorphisms, mycobacteria, alcohol, biomass, cigarette smoke) stimulates TNF- $\alpha$ production by T lymphocytes, which quickly causes macrophage, granulocyte, and cytolytic $\mathrm{T}$ lymphocyte activation and mat- uration, as well as T lymphocyte proliferation. Thus, a positive feedback loop is established, which promotes granuloma formation and maintenance by recruiting macrophages and lymphocytes to the infection site to contain the mycobacteria [46]. This mechanism could explain the possible protective behaviour observed, and we observe that this correlates with our findings because the association is suppressed by exposure to environmental factors.

On the other hand, similar frequencies for the TNF -308G/A polymorphism to the ones we report in this study have been found in Iran [29, 47], Macedonia [48], and Colombia [29]. Merza et al. [47] found an association between this polymorphism and tuberculosis. However, it was with the $-308 \mathrm{~A}$ allele as a risk factor, the other studies did not find any association. This seem- 
I. Torres Ramírez de Arellano, C. Salinas Lara, L.M. Torres Espíndola, M.J. Castillejós López, A. Jara Prado, R. Velazquez Cruz, J.L. Guerrero Camacho, N. Patiño, J.D. Rembao Bojórquez, M.L. Tena Suck

Table V. TNF -308G/-238G haplotype associations between groups and exposure factors

\begin{tabular}{|c|c|c|c|c|c|}
\hline Group & Exposure & & $P$-value & OR & $95 \% \mathrm{Cl}$ \\
\hline \multirow[t]{8}{*}{ PTB vs. TC } & Occupational biomass smoke & $(+)$ & 0.77 & 0.87 & $0.34-2.22$ \\
\hline & & $(-)$ & 0.49 & 1.38 & $0.55-3.47$ \\
\hline & In-home biomass smoke & $(+)$ & 0.66 & 0.82 & $0.33-2.04$ \\
\hline & & $(-)$ & 0.31 & 1.61 & $0.64-4.03$ \\
\hline & Cigarettes & $(+)$ & 0.38 & 0.45 & $0.07-2.77$ \\
\hline & & $(-)$ & 0.4 & 1.34 & $0.67-2.68$ \\
\hline & Alcohol & $(+)$ & 0.2 & 0.46 & $0.13-1.56$ \\
\hline & & $(-)$ & 0.36 & 1.44 & $0.66-3.11$ \\
\hline \multirow[t]{8}{*}{ PTB vs. CC } & Occupational biomass smoke & $(+)$ & 0.41 & 0.62 & $0.19-1.97$ \\
\hline & & $(-)$ & 0.57 & 1.34 & $0.50-3.60$ \\
\hline & In-home biomass smoke & $(+)$ & 0.76 & 0.85 & $0.30-2.40$ \\
\hline & & $(-)$ & 0.63 & 1.28 & $0.47-3.5$ \\
\hline & Cigarettes & $(+)$ & 0.2 & 0.26 & $0.03-2.25$ \\
\hline & & $(-)$ & 0.54 & 1.27 & $0.59-2.72$ \\
\hline & Alcohol & $(+)$ & 0.2 & 0.42 & $0.11-1.63$ \\
\hline & & $(-)$ & 0.6 & 1.26 & $0.53-2.99$ \\
\hline \multirow[t]{8}{*}{ PTB vs. NCC } & Occupational biomass smoke & $(+)$ & 0.69 & 1.24 & $0.42-3.66$ \\
\hline & & $(-)$ & 0.51 & 1.44 & $0.48-4.3$ \\
\hline & In-home biomass smoke & $(+)$ & 0.66 & 0.78 & $0.25-2.39$ \\
\hline & & $(-)$ & 0.12 & 2.31 & $0.79-6.76$ \\
\hline & Cigarettes & $(+)$ & 0.72 & 0.71 & $0.10-4.90$ \\
\hline & & $(-)$ & 0.38 & 1.46 & $0.63-3.42$ \\
\hline & Alcohol & $(+)$ & 0.33 & 0.50 & $0.12-2.02$ \\
\hline & & $(-)$ & 0.24 & 1.75 & $0.69-4.46$ \\
\hline
\end{tabular}

PTB - tuberculosis patients, CC - consanguineous controls, NCC - nonconsanguineous controls, TC - total controls.

ingly paradoxical finding needs to be explained in the light of existing literature regarding tuberculosis and TNF polymorphisms.

The genetic structure of the Mexican Mestizo population consists of three primary sources: Amerindians, Caucasians, and Africans [49]. This unique admixture, when compared with other populations, may have some influence on the frequency of the polymorphisms, causing the discrepancy or coincidence observed in our results with respect to other researchers. Supporting this theory, a 2012 meta-analysis involving 18 studies [50] regarding the $T N F-308 \mathrm{G} / \mathrm{A}$ polymorphism and tuberculosis susceptibility revealed that the $-308 \mathrm{~A}$ allele was had a significant risk among Asians, but not in Caucasians, who have an important contribution to the genetic component of the Mexican mestizos.
It has been widely validated that TNF- $\alpha$ inhibitors are drugs that can be used to treat inflammatory conditions successfully, such as rheumatoid arthritis (RA), juvenile arthritis, psoriatic arthritis, inflammatory bowel disease, and psoriasis, among others. These drugs reduce inflammation and stop disease progression by targeting the inflammation-causing TNF- $\alpha$. However, a major concern is that patients receiving this therapy have an increased risk of bacterial infection, particularly TB reactivation/infection, which interferes with innate immune responses, such as phagosome maturation and apoptosis through complement-mediated cytotoxicity [51]. It is important to clarify that in our study none of the patients or controls had any indications for anti-TNF- $\alpha$ treatment. Our work has the advantage of the available demographic data, which was collected based on a validated ques- 
Exposure to biomass smoke, cigarettes, and alcohol modifies the association between tumour necrosis factor $(-308 \mathrm{G} / \mathrm{A},-238 \mathrm{G} / \mathrm{A})$ polymorphisms and tuberculosis in Mexican carriers

Table VI. TNF-308G/-238A haplotype associations between groups and exposure factors

\begin{tabular}{|c|c|c|c|c|c|}
\hline Group & Exposure & & $P$-value & OR & $95 \% \mathrm{Cl}$ \\
\hline \multirow[t]{8}{*}{ PTB vs. TC } & Occupational biomass smoke & $(+)$ & 0.55 & 1.54 & $0.37-6.39$ \\
\hline & & $(-)$ & 0.25 & 1.88 & $0.63-5.62$ \\
\hline & In-home biomass smoke & $(+)$ & 0.55 & 1.51 & $0.39-5.91$ \\
\hline & & $(-)$ & 0.37 & 1.66 & $0.54-5.04$ \\
\hline & Cigarettes & $(+)$ & NC & NC & NC \\
\hline & & $(-)$ & 0.52 & 1.32 & $0.56-3.15$ \\
\hline & Alcohol & $(+)$ & 0.43 & 2.00 & $0.35-11.45$ \\
\hline & & $(-)$ & 0.37 & 1.58 & $0.57-4.39$ \\
\hline \multirow[t]{8}{*}{ PTB vs. CC } & Occupational biomass smoke & $(+)$ & 0.52 & 1.75 & $0.31-9.97$ \\
\hline & & $(-)$ & 0.65 & 1.30 & $0.42-4.04$ \\
\hline & In-home biomass smoke & $(+)$ & 0.75 & 0.80 & $0.20-3.17$ \\
\hline & & $(-)$ & 0.37 & 1.75 & $0.50-6.06$ \\
\hline & Cigarettes & $(+)$ & NC & NC & NC \\
\hline & & $(-)$ & 0.9 & 1.06 & $0.42-2.67$ \\
\hline & Alcohol & $(+)$ & 0.72 & 1.38 & $0.23-8.48$ \\
\hline & & $(-)$ & 0.62 & 1.32 & $0.44-3.96$ \\
\hline \multirow[t]{8}{*}{ PTB vs. NCC } & Occupational biomass smoke & $(+)$ & 0.75 & 1.32 & $0.23-7.58$ \\
\hline & & $(-)$ & 0.06 & 6.47 & $0.74-56.28$ \\
\hline & In-home biomass smoke & $(+)$ & 0.06 & 1.89 & $1.56-2.30$ \\
\hline & & $(-)$ & 0.58 & 1.50 & $0.35-6.41$ \\
\hline & Cigarettes & $(+)$ & NC & NC & NC \\
\hline & & $(-)$ & 0.23 & 2.21 & $0.58-8.38$ \\
\hline & Alcohol & $(+)$ & 0.20 & 4.46 & $0.37-53.7$ \\
\hline & & $(-)$ & 0.27 & 2.39 & $0.49-11.71$ \\
\hline
\end{tabular}

PTB - tuberculosis patients, CC - consanguineous controls, NCC - nonconsanguineous controls, TC - total controls, NC - no calculable

A
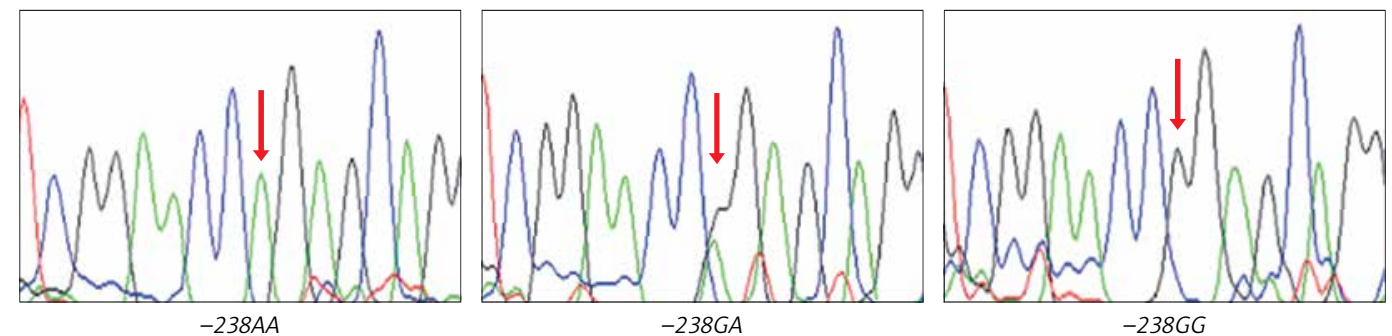

B
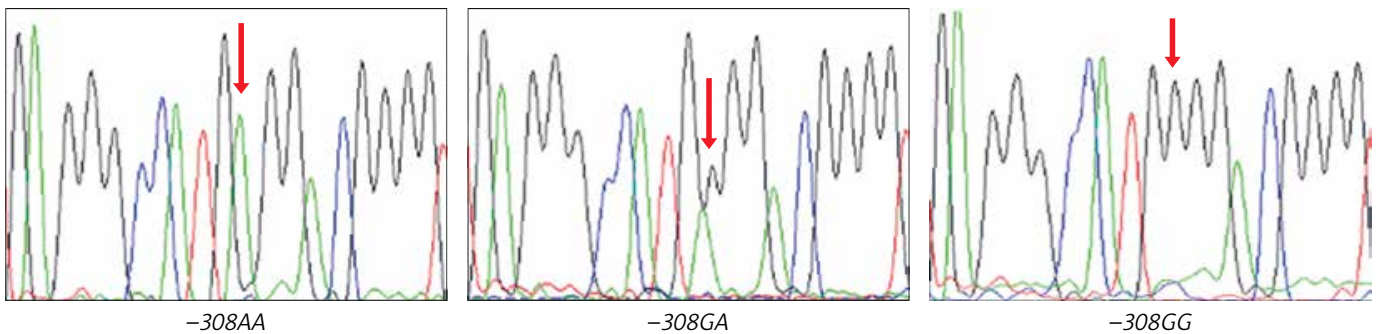

Figure 2. Electropherograms for TNF-238G/A polymorphism (A), TNF-308G/A polymorphism (B) 
tionnaire that is one of the most complete used for respiratory disease epidemiology [52, 53]. Additionally, validation of our technique makes the exposure measurement (polymorphisms) trustworthy. However, biomass smoke exposure levels could not be quantified with adequate equipment, nor were tobacco or alcohol confirmed by lab tests. The only way this information was obtained was through the validated questionnaire, so this could be a limiting factor for our study, which could diminish the precision of these variables due to possible memory bias from interviewed patients. Even though our work is one of the few with a large number of patients analysed, future studies will require even larger sample sizes to conclusively determine the influence of the TNF polymorphisms on tuberculosis in the presence of biomass smoke, cigarettes, and alcohol.

In conclusion, the results indicate that the TNF $-308 \mathrm{~A}$ allele and the $-308 \mathrm{~A} /-238 \mathrm{G}$ haplotype are associated with tuberculosis and exposure to biomass smoke, cigarettes, and alcohol. However, no association for the $-238 \mathrm{G} / \mathrm{A}$ polymorphism was found. Our results provide insight into a possible protective role of TNF polymorphisms in tuberculosis in our population.

\section{Acknowledgments}

We would like to thank all who participated in the making of this study.

\section{Conflict of interest}

The authors declare no conflict of interest.

\section{References}

1. Kałka D, Karpiński L, Gebala J, et al. Sexual health of male cardiac patients - present status and expectations of patients with coronary heart disease. Arch Med Sci 2017; 13: 302-10.

2. Jankowski P, Czarnecka D, Badacz L, et al. Practice setting and secondary prevention of coronary artery disease. Arch Med Sci 2018; 14: 979-87.

3. Chen M, Deng J, Su C, et al. Impact of passive smoking, cooking with solid fuel exposure, and MBL/MASP-2 gene polymorphism upon susceptibility to tuberculosis. Int J Infect Dis 2014; 29: 1-6.

4. Demirjian L, Abboud R, Li H, Duronio V. Acute effect of cigarette smoke on TNF-alpha release by macrophages mediated through the erk1/2 pathway. Biochim Biophys Acta 2006; 1762: 592-7.

5. Patra J, Bhatia M, Suraweera W, Morris S, Patra C, Gupta P. Exposure to second-hand smoke and the risk of tuberculosis in children and adults: a systematic review and meta-analysis of 18 observational studies. PLoS Med 2015; 12: e1001835.

6. Swiston J, Davidson W, Attridge S, Li G, Brauer M, Van Eeden S. Wood smoke exposure induces a pulmonary and systemic inflammatory response in firefighters. Eur Respir J 2008; 32: 129-38.

7. Selassie A, Wilson D. Quantification of the risk of recurrence in tuberculosis. Ann Epidemiol 2002; 12: 524.
8. Khudzik L, Pankratova D, Riabov B, Vygodchikov I. Social and clinical characteristics of progressive forms of pulmonary tuberculosis in Saratov and Saratov region. Probl Tuberk 2001; 6: 24-7.

9. Breitenfeld D, Trkanjec Z, Thaller V, Breitenfeld T, DeSyo D, Golik V. Tuberculosis and alcoholism in Croatia. Coll Antropol 1998; 22: S217-22.

10. Erdem B, Peker N, Inci A, et al. Pelvic tuberculosis mimicking ovarian cancer: a series of 13 cases. Arch Med Sci Civil Dis 2017; 2: 177-81.

11. Jelski W, Laniewska-Dunaj M, Orywal K, Kochanowicz J, Rutkowski R, Szmitkowski M. The diagnostic value of alcohol dehydrogenase (ADH) isoenzymes and aldehyde dehydrogenase (ALDH) measurement in the sera of patients with brain tumor. Arch Med Sci 2017; 13: 346-52.

12. Grove J, Daly A, Bassendine M, Day C. Association of a tumor necrosis factor promoter polymorphism with susceptibility to alcoholic steatohepatitis. Hepatology 1997; 26: 143-6.

13. McClain C, Cohen D. Increased tumor necrosis factor production by monocytes in alcoholic hepatitis. Hepatology 1989; 9: 349-51.

14. Kamimura S, Tsukamoto $\mathrm{H}$. Cytokine gene expression by Kupffer cells in experimental alcoholic liver disease. Hepatology 1995; 21: 1304-9.

15. Pleśniak R, Wawrzynowicz-Syczewska M. Polymorphism of IL28B gene and response to pegylated interferon alpha2a in chronic hepatitis B. Arch Med Sci 2017; 13: 70-7.

16. Stickel F, Sterreicher C. The role of genetic polymorphisms in alcoholic liver disease. Alcohol Alcohol 2006; 41: 209-24.

17. Kaluza W, Reuss E, Grossmann S, et al. Different transcriptional activity and in vitro TNF-alpha production in psoriasis patients carrying the TNF-alpha 238A promoter polymorphism. J Invest Dermatol 2000; 114: 1180-3.

18. Teixeira A, Mendes C, Marano L, et al. Alleles and genotypes of polymorphisms of IL-18, TNF-a and IFN-C are associated with a higher risk and severity of hepatocellular carcinoma (HCC) in Brazil. Hum Immunol 2013; 74: 1024-9.

19. Fan H, Wang Z, Feng F, et al. Association of TNF-alpha $-238 \mathrm{G} / \mathrm{A}$ and $-308 \mathrm{G} / \mathrm{A}$ gene polymorphisms with pulmonary tuberculosis among patients with coal worker's pneumoconiosis. Biomed Environ Sci 2010; 23: 137-45.

20. Cheng K, Zhao Y, Liu L, Wan J. Tumor necrosis factor-alpha 238 G-A polymorphism and risk of hepatocellular carcinoma: evidence from a meta-analysis. Asian Pacific J Cancer Prev 2013; 14: 3275-9.

21. Sobjanek M, Zabłotna M, Michajłowski I, et al. -308 G/A TNF-alpha gene polymorphism influences the course of basal cell carcinoma in a Polish population. Arch Med Sci 2015; 11: 599-604.

22. Zhang Z, Zhu H, Pu X, et al. Association between tumor necrosis factor alpha -238G/A polymorphism and tuberculosis susceptibility: a meta-analysis study. BMC Infect Dis 2012; 12: 328-35.

23. Amirzargar A, Rezaei N, Jabbari $\mathrm{H}$, et al. Cytokine single nucleotide polymorphisms in Iranian patients with pulmonary tuberculosis. Eur Cytokine Netw 2006; 17: 84-9.

24. Hogg J. Pathophysiology of airflow limitation in chronic obstructive pulmonary disease. Lancet 2004; 364: 709-21.

25. Gingo M, Silveira L, Miller Y, et al. Tumour necrosis factor gene polymorphisms are associated with COPD. Eur Respir J 2008; 31: 1005-12.

26. Buffone GJ, Darlington GJ. Isolation of DNA from biological specimens without extraction with phenol. Clin Chem 1985; 31: 164-5. 
27. Lo H, Kuo D, Chen Y. Impact of beverage consumption, age, and site dependency on dual energy X-ray absorptiometry (DEXA) measurements in perimenopausal women: a prospective study. Arch Med Sci 2017; 13: 1178-87.

28. Scola L, Crivello A, Marino V, et al. IL-10 and TNF-alpha polymorphisms in a sample of Sicilian patients affected by tuberculosis: implication for ageing and life span expectancy. Mech Ageing Dev 2003; 124: 569-72.

29. Correa P, Gomez L, Cadena J, Anaya J. Autoimmunity and tuberculosis. Opposite association with TNF polymorphism. J Rheumatol 2005; 32: 219-24.

30. Varahram M, Farnia P, Javad M, Afraei M, Kazempour M, Akbar A. Association of Mycobacterium tuberculosis lineages with IFN-gamma and TNF-alpha gene polymorphisms among pulmonary tuberculosis patient. Mediterr J Hematol Infect Dis 2014; 6: e2014015.

31. Vargas G, Ramirez J, Juarez T, Ramirez S, Carrillo S, Frago so J. Distribution of the IL-1RN, IL-6, IL- 10, INF-gamma, and TNF-alpha gene polymorphisms in the Mexican population. Genet Test Mol Biomarkers 2012; 16: 1246-53.

32. Hedayati M, Sharifi K, Rostami F, Daneshpour M, Zarif M Azizi F. Association between TNF-a promoter G-308A and G-238A polymorphisms and obesity. Mol Biol Rep 2012; 39: 825-9.

33. Retsas T, Huse K, Lazaridis LD, et al. Haplotypes composed of minor frequency single nucleotide polymorphisms of the TNF gene protect from progression into sepsis: a study using the new sepsis classification. Int J Infect Dis 2018; 67: 102-6.

34. Kolovou V, Bilianou H, Giannakopoulou V, et. al. Five gene variants in nonagenarians, centenarians and average individuals. Arch Med Sci 2017; 13: 1130-41.

35. Stämpfli M, Anderson G. How cigarette smoke skews immune responses to promote infection, lung disease and cancer. Nat Rev Immunol 2009; 9: 377-84.

36. Lakshmi P, Virdi N, Thakur J, Smith K, Bates M, Kumar R. Biomass fuel and risk of tuberculosis: a case-control study from Northern India. J Epidemiol Community Health 2012; 66: 457-61.

37. Sada I, Ocaña R, Torre L. Humo de biomasa, inmunidad innata y Mycobacterium tuberculosis. Neumol Cir Torax 2015; 74: 118-26.

38. Migliaccio C, Kobos E, King Q, Porter V, Jessop F, Ward T. Adverse effects of wood smoke PM (2.5) exposure on macrophage functions. Inhal Toxicol 2013; 25: 67-76.

39. Renwick L, Brown D, Clouter A, Donaldson K. Increased inflammation and altered macrophage chemotactic responses caused by two ultrafine particle types. Occup Environ Med 2004; 61: 442-7.

40. Hernandez E, Brauer M, Perez J, Vedal S. Wood smoke exposure and lung adenocarcinoma in non-smoking Mexican women. Int J Tuberc Lung Dis 2004; 8: 377-83.

41. Ramanakumar A, Parent M, Siemiatycki J. Risk of lung cancer from residential heating and cooking fuels in Montreal, Canada. Am J Epidemiol 2007; 165: 634-42.

42. Xu X, Niu T, Christiani D. Occupational and environmental risk factors for asthma in rural communities in China. Int J Occup Environ Health 1996; 2: 172-6.

43. Ansari A, Hasan Z, Dawood G, Hussain R. Differential combination of cytokine and interferon-gamma +874T/A polymorphisms determines disease severity in pulmonary tuberculosis. PLoS One 2011; 6: e27848.

44. Ramakrishnan L. Revisiting the role of the granuloma in tuberculosis. Nat Rev 2012; 12: 352-66.

45. Jasenosky L, Scriba T, Hanekom W, Goldfeld A. T cells and adaptive immunity to Mycobacterium tuberculosis in humans. Immunol Rev 2015; 264: 74-87.
46. Dheda K, Schwander S, Zhu B, Zyl R, Zhang Y. The immunology of tuberculosis: from bench to bedside. Respirology 2010; 15: 433-50.

47. Merza M, Farnia P, Anoosheh S, et al. The NRAMPI, VDR and TNF-alpha gene polymorphisms in Iranian tuberculosis patients: the study on host susceptibility. Braz J Infect Dis 2009; 13: 252-6.

48. Trajkov D, Trajchevska M, Arsov T, et al. Association of 22 cytokine gene polymorphisms with tuberculosis in Macedonians. Indian J Tuberc 2009; 56: 117-31.

49. Lisker R, Ramirez V, Babinsky V. Genetic structure of autochthonous populations of Meso-America: Mexico. Hum Biol 1996; 68: 394-5.

50. Wang Q, Zhan P, Qiu LX, Qian Q, Yu LK. TNF-308 gene polymorphism and tuberculosis susceptibility: a meta-analysis involving 18 studies. Mol Biol Rep 2012; 39: 3393-400.

51. Harris J, Keane J. How tumour necrosis factor blockers interfere with tuberculosis immunity. Clin Exp Immunol 2010; 161: 1-9.

52. Menezes AM, Victora CG, Perez-Padilla R, PLATINO Team. The Platino project: methodology of a multicenter prevalence survey of chronic obstructive pulmonary disease in major Latin American cities. BMC Med Res Methodol 2004; 4: 15

53. Perez-Padilla R, Wehrmeister FC, Celli BR, et al. Reliability of FEV1/FEV6 to diagnose airflow obstruction compared with FEV1/FVC: the PLATINO longitudinal study. PLoS One 2013; 8: e67960. 